\title{
Sorption of potential ionic pollutants on oil shale and its non-series composite sorbents
}

\author{
M. Molnár ${ }^{1} \cdot$ R. Földényi ${ }^{1} \cdot 0$. Horváth $^{2}(1)$
}

Received: 8 May 2020 / Revised: 10 November 2020 / Accepted: 27 November 2020 / Published online: 23 December 2020

(C) The Author(s) 2020

\begin{abstract}
Huge amounts of anthropogenic environmental pollutants appearing in nature mean an emerging problem. Oil shale is a convenient candidate, wherewith these contaminations can be removed from our natural environment, taking into account its sorption ability and low price. However, oil shale has a crumbling nature, which restricts its facile usage. Hence, oil shale was transformed into more handleable forms, using binding materials. Two oil shale composite forms were prepared by applying sodium alginate and agar. A cationic and an anionic chemicals, benzyltriethylammonium chloride and sodium 2,3-diisopropylnaphthalene-1-sulfonate, respectively, were used as model pollutants, and their sorptions on these newly prepared composites were studied. Sorption properties of oil shale powder and oil shale composites were compared. In the composite materials, oil shale properly sorbed the model pollutants (the binding material did not cover the sorption sites); furthermore, oil shale composites had significantly higher removal efficiency compared to that of the oil shale powder: $208 \pm 15.6$ (oil shale-agar) and $171 \pm 22.8$ (oil shale-alginate) vs $140 \pm 11.1 \mu \mathrm{mol} / \mathrm{g}$ for the cationic compound; $151 \pm 1.6$ (oil shale-agar) and $165 \pm 7.6$ (oil shale-alginate) vs $81.5 \pm 2.6 \mu \mathrm{mol} / \mathrm{g}$ for the anionic compound. Results of diffusion models for the two composites show that the opposite charges of the solutes largely influence the rate of their diffusion, owing to the interaction between the solute and the composite material. These results indicate that oil shale and its composites are applicable candidates as sorbents, from which the most effective one can be chosen by considering the chemical properties of the actual pollutant to be removed.
\end{abstract}

Keywords Agar $\cdot$ Alginate $\cdot$ Benzyltriethylammonium chloride $\cdot$ Diffusion $\cdot$ Oil shale $\cdot$ Sodium 2,3-diisopropylnaphthalene1-sulfonate

Editorial responsibility: Josef Trögl.

R. Földényi unfortunately passed away in 2019.

Supplementary information The online version of this article (https://doi.org/10.1007/s13762-020-03052-w) contains supplementary material, which is available to authorized users.

O. Horváth

horvath.otto@mk.uni-pannon.hu

1 Soós Ernő Water Technology Research and Development Center, University of Pannonia, Egyetem Str. 10, Veszprém 8200, Hungary

2 Department of General and Inorganic Chemistry, Center for Natural Sciences, University of Pannonia, Egyetem Str. 10, Veszprém 8200, Hungary

$\begin{array}{ll}\text { Abbreviations and Nomenclature } \\ \text { BTEAC } & \text { Benzyltriethylammonium chloride } \\ \text { DIPNS } & \text { Sodium } \\ & \text { 2,3-diisopropylnaphthalene-1-sulfonate } \\ \text { TOC } & \text { Total organic carbon } \\ \text { BET } & \text { Brunauer-Emmett-Teller } \\ \text { SEM } & \text { Scanning electron microscope } \\ \text { CMC } & \text { Critical micelle concentration } \\ \text { STP } & \text { Standard temperature and pressure } \\ q_{\mathrm{e}} & \text { Sorption capacity at equilibrium }(\mathrm{mol} / \mathrm{g}) \\ c_{\mathrm{e}} & \text { Equilibrium solute concentration }(\mathrm{mol} / \mathrm{L}) \\ R^{2} & \text { Coefficient of determination } \\ \text { RMSE } & \text { Root-mean-square error } \\ \text { AICc } & \text { Corrected Akaike information criterion } \\ Q_{\mathrm{max}} & \text { Maximum amount of solute adsorbed for } \\ & \text { monolayer coverage of the surface }(\mathrm{mol} / \mathrm{g}) \\ K_{\mathrm{L}} & \text { Langmuir constant }(\mathrm{L} / \mathrm{mol}) \\ K_{\mathrm{F}} & \text { Freundlich constant }\left(\mathrm{L}^{1 / n} /\left(\mathrm{mol}{ }^{((1 / n)-1)} \mathrm{g}\right)\right) \\ n & \text { Freundlich constant }(\text { dimensionless })\end{array}$




\begin{tabular}{|c|c|}
\hline $\mathrm{D}$ & Diffusion coefficient $\left(\mathrm{m}^{2} / \mathrm{s}\right)$ \\
\hline$t$ & Time (s) \\
\hline$C_{\mathrm{L}}^{\mathrm{D}}(t)$ & $\begin{array}{l}\text { Concentration of solute in the solution } \\
(\mathrm{mol} / \mathrm{L})\end{array}$ \\
\hline$C_{\mathrm{LO}}$ & $\begin{array}{l}\text { Initial concentration of solute in the solution } \\
(\mathrm{mol} / \mathrm{L})\end{array}$ \\
\hline$C_{\mathrm{LE}}$ & $\begin{array}{l}\text { Equilibrium concentration of solute in the } \\
\text { solution }(\mathrm{mol} / \mathrm{L})\end{array}$ \\
\hline$V_{\mathrm{g}}$ & Total volume of the sorbent $\left(\mathrm{m}^{3}\right)$ \\
\hline$V^{6}$ & Volume of the liquid phase $\left(\mathrm{m}^{3}\right)$ \\
\hline$a$ & Radius of the sorbent spheres (m) \\
\hline$K$ & Partition coefficient of solute (dimensionless) \\
\hline$C(x, y, z, t)$ & $\begin{array}{l}\text { Time- and place-dependent concentration of } \\
\text { solute in the spheres }(\mathrm{mol} / \mathrm{L})\end{array}$ \\
\hline$N$ & $\begin{array}{l}\text { Total number of experimental points } \\
\text { (dimensionless) }\end{array}$ \\
\hline$q_{n}$ & $\begin{array}{l}\text { Nonzero positive roots of equation } \\
\tan \left(q_{n}\right)=\frac{3 \cdot q_{n}}{\alpha \cdot q^{2}+3} \text { (dimensionless) }\end{array}$ \\
\hline$\alpha$ & $\begin{array}{l}\text { Alpha factor, defined by equality } \alpha=\frac{C_{\mathrm{LE}}}{C_{\mathrm{LO}}-C_{\mathrm{LE}}} \\
\text { (dimensionless) }\end{array}$ \\
\hline$L$ & Height of the right circular cylinder (m) \\
\hline$p_{n}$ & $\begin{array}{l}\text { Nonzero positive roots of equation } \\
\tan \left(p_{n}\right)=-\alpha \cdot p_{n} \text { (dimensionless) }\end{array}$ \\
\hline$M_{t}$ & $\begin{array}{l}\text { Sorbed amount of solute by sorbent until } t \\
\text { moment (mol) }\end{array}$ \\
\hline$M_{\infty}$ & $\begin{array}{l}\text { Sorbed amount of solute by sorbent at equi- } \\
\text { librium (mol) }\end{array}$ \\
\hline
\end{tabular}

\section{Introduction}

Anthropogenic pollutants in nature have been a huge problem for a long time. There were numerous attempts in the last several years to remove these chemicals owning various properties (Shawabkeh 2006; Ayar et al. 2008; Zhao et al. 2014; Acar et al. 2015; Hassani et al. 2015; İnal and Erduran 2015; Belhouchat et al. 2017; Chen et al. 2017; Dinu et al. 2017; Phiri et al. 2019; Duman et al. 2020). One of the most widely used technics is sorption, wherewith these contaminants can be removed. There are diverse materials which are eligible to be used as a sorbent. Unfortunately, the price of some of these sorbents is too high to apply regularly in the industry; therefore, new low-priced materials having convenient sorption properties tend to be used for purifying the contaminated waters or liquids. Among these materials, oil shale is one of the most promising natural material, which has been used as a sorbent in unmodified or modified forms (Shawabkeh 2006; Ayar et al. 2008; Zhao et al. 2014; Acar et al. 2015). Oil shale can be found worldwide in giant amount, also in Hungary. Oil shale has no universally accepted definition. The most widespread definition is "lamellar sedimentary rock, its ash content is higher than
$33 \%$, its organic content can hardly be extracted by generally used organic solvents, but it can be transformed to oil by heat convection" (Hetényi 1996). Organic material content of oil shale varies between 5 and $50 \%$, but regarding some deposits, this value can reach $90 \%$. This organic material is primarily kerogen. The main building blocks of Hungarian oil shale are residue of Botryococcus braunii microalgae, montmorillonite, illite and calcite. These components had been transformed to oil shale for about 5 million years, while microalgae accumulated in the deposit. The formation of oil shale took place in non-active volcanic craters, filled lakes or closed sea lagoons. Carbon-dioxiderich and higher-temperature environment was favorable for a fast increment of Botryococcus braunii microalgae, which facilitated the evolution of oil shale. According to the location of formation, maar- and lagoon-type oils shale can be distinguished. The application of oil shale is multifarious: it is used for production of liquid fuel as a raw material, as a fuel, starter fertilizer, soil-ameliorating agent, adsorbent for bonding gas-, liquid- and solid-phase contaminants. It is also used for healing articular, rheumatic, psoriasis diseases and as a skin-regenerative agent (Hetényi 1996; Solti 2003). Only one problem arises regarding oil shale, namely its crumbling feature, which hampers its effortless application. Accordingly, applying binding materials can solve this disadvantage.

Numerous binders, immobilizing agents have been described in the literature, but just a few of them were adequate for production of oil shale composites, which were convenient for the removal of pollutants from aqueous phase. Thus, two types of oil shale composites (depending on the immobilizers) could be created, which were appropriate as sorbents in sorption experiments. The immobilizing agents used for the preparation of the two types of composites were alginate and agar materials.

Alginate is a natural anionic polysaccharide built up by residues of 1,4-linked $\beta$-D-mannuronic acid and $\alpha$-Lguluronic acid. Alginate can be extracted from various brown algae and several Pseudomonas species. The unfixed ratio of residues of mannuronic acid and guluronic acid fractions varies the physical and chemical properties of alginate in wide ranges. The higher ratio of mannuronic acid quantity, the more flexible gel can be obtained and vice versa. Several divalent cations can cross-link the copolymer alginate chains, as a result, gel phase is formed from alginate solution. The diverse properties can be attributed to the fact that the residues of guluronic acid have higher affinity to the divalent cations than the residues of mannuronic acid; moreover, the different divalent cations have different affinities to the monomers of alginate (de Vos et al. 2014; Hecht and Srebnik 2016; Wang et al. 2019). Utilization of alginate is multivarious, for example, it has been already used for removing pollutants, such as 4-nitrophenol (Peretz 
and Cinteza 2008), toluene (Phiri et al. 2019) or dyes (Hassani et al. 2015; İnal and Erduran 2015; Belhouchat et al. 2017; Dinu et al. 2017). Furthermore, numerous studies can be found in the literature, in which alginate was used as an encapsulation, immobilizing media, where such as Vitamin $B_{12}$ and polyethylene glycol (Puguan et al. 2015), $\beta$-glucuronidase enzyme ( $\mathrm{Li}$ et al. 2009), enzyme yeast alcohol dehydrogenase (Xu et al. 2007), glucose oxidase enzyme (Blandino et al. 2001), ovalbumin protein (Yu et al. 2019) or thyme extract (Stojanovic et al. 2012) were immobilized.

Agar is also a natural polysaccharide, which can be extracted from cell walls of red algae. Agar has two main fractions: agarose and agaropectin. The agarose fraction is largely responsible for the gelling capability of agar. Although agaropectin itself does not have gelling capability, it can enhance the gelling transformation (Nishinari and Fang 2017). The agarose fraction consists of alternating monomers of 1,3-linked $\beta$-D-galactopyranose and 1,4-linked 3,6 -anhydro- $\alpha$-L-galactopyranose. These two monomers compose agarobiose units, whereby around 400 units produce long chains. The agaropectin fraction is more complex, its general chemical formula cannot be accurately provided. Its frame structure is the same as that of agarose, but with various amounts of the residues are replaced by pyruvic acid ketal, 4,6-O-(1-carboxyethylidene)D-galactopyranose and different methylated or sulfated sugar units. In the course of sol-gel transition, at high temperature, the random coil chains in solution organize into double helices, which further form into networks of double helices, when the temperature decreases. Thus, rigid gel emerges at low temperature (de Vos et al. 2014; Nishinari and Fang 2017). Agar and its component, agarose have been utilized for numerous purposes, especially for promoting microbiological processes. Besides, they have also been used as sorption and immobilizing materials in composites or on their own. For instance, adsorption of $\mathrm{Mn}$ (II), Co(II) (Gupta et al. 2008), $\mathrm{Cu}$ (II) (Zhang et al. 2015, 2017), $\mathrm{Pb}$ (II), Co(II) (Zhang et al. 2017) and Bovine serum albumin (Asgari et al. 2014) were investigated on agar or agar composite. Although alginate and agar are efficient sorption materials, their relatively high price limits their practical application. The utilization of oil shale, however, is advantageous, due to its low price, which enables its wide range of usage.

Two surfactants as model pollutants were chosen to be removed by adsorption on the composites: benzyltriethylammonium chloride (BTEAC) and sodium 2,3-diisopropylnaphthalene-1-sulfonate (DIPNS). BTEAC is a well-known phase-transfer catalyst, which is widely used in heterogeneous chemical reactions, especially in the area of organic chemistry (Entezari and Shameli 2000). DIPNS has a hydrotropic and surfactant nature, thus it is used as a forming agent, particularly in the case of formulations of pesticides (Burns and Duliba 2000; Joó et al. 2015). Considering the frequent utilization of these two surfactants, they have potential risks of becoming environmental pollutants, when they get into the soil or natural waters. During the selection of these chemicals, the main viewpoint was primarily their diverse chemical properties, and secondly the possibility of their emergence in nature.

In this paper, the term of sorption is purposely used instead of adsorption because in the case of oil shale and oil shale composites adsorption and absorption procedures took place simultaneously.

The main aim of this work was to investigate how and in which form the extremely low-priced oil shale could be utilized as sorption material to remove various environmental pollutions in the most efficient way for future usage. Exploring the sorption behavior of the newly prepared composites in the presence of the selected model pollutants, and comparing these results to those regarding the raw oil shale powder, a conclusion can be drawn whether these new composite materials efficiently remove the chemicals from the liquid phase or not, and the advantage or disadvantage of their application can be revealed. Moreover, explanation can be provided from the adsorption isotherms and the results of the diffusion calculation, namely what kind of interactions arise between the ionic solute and alginate or oil shale in the composite materials.

This work was conducted between 2018 and 2020, in the University of Pannonia, Veszprém, Hungary.

\section{Materials and methods}

\section{Materials}

Maar-type oil shale originated from Pula, Hungary. Before using the mining raw oil shale material, it was air-dried at room temperature $\left(25^{\circ} \mathrm{C}\right)$ and milled under the size of $\varnothing<800 \mu \mathrm{m}$. Benzyltriethylammonium chloride (BTEAC), sodium 2,3-diisopropylnaphthalene-1-sulfonate.

(DIPNS), sodium alginate, agar and calcium chloride were purchased from Merck KGaA, Biosynth AG, SigmaAldrich Co., Naturtrade Hungary Kft. and Lach-Ner s.r.o., respectively. All chemicals were analytical grade, and used without further purification. Figure S1 in the Supporting Information (SI) shows the chemical structure of BTEAC and DIPNS, and their molar mass values are provided.

\section{Preparation of alginate and oil shale-alginate beads}

The procedure of the preparation of alginate beads was very similar to the method described in the literature ( $\mathrm{Li}$ et al. 2009). $2.5 \%(\mathrm{w} / \mathrm{v}$ ) of sodium alginate solution was prepared by dissolving sodium alginate powder in deionized water. Oil shale-alginate beads were produced by mixing swelled 
oil shale (in 5:4 mass ratio of oil shale and deionized water) and $2.5 \%(\mathrm{w} / \mathrm{v})$ of sodium alginate solution homogeneously (final mass ratio of oil shale and alginate powder was 8:1). The obtained solution or mixture was added dropwise to $0.2 \mathrm{~mol} / \mathrm{L} \mathrm{CaCl}_{2}$ solution. After standing in the $\mathrm{CaCl}_{2}$ solution overnight, the formed beads were filtered and washed with deionized water. Mean diameter of the alginate and oil shale-alginate beads was $\varnothing$ : 5-6 and 6-8 $\mathrm{mm}$, respectively.

\section{Preparation of agar layer and oil shale-agar composite}

Agar suspension was made by mixing agar powder with hot deionized water at a final concentration of $0.66 \%(\mathrm{w} / \mathrm{v})$. Agar layer was obtained by pouring definite quantity of this suspension into crystallizing dishes. Oil shale-agar composite was prepared by mixing semi-cooled agar suspension with swelled oil shale (in 5:4 mass ratio of oil shale and deionized water). The final mass ratio of oil shale and agar powder was 30.3:1. This mixture was poured into crystallizing dishes. Both types of suspensions were cooled to room temperature before sorption experiments.

\section{Sorption experiments}

Five grams of oil shale powder was weighed into $250-\mathrm{mL}$ stoppered Erlenmeyer flasks. Five milliliters of deionized water was added to this oil shale powder. This weighed oil shale was left to swell overnight at room temperature.

In the case of oil shale-alginate, composite beads containing $5 \mathrm{~g}$ of oil shale powder or alginate beads were weighed into 250-mL stoppered Erlenmeyer flasks. The mass of alginate of the weighed oil shale-alginate beads was identical with the weighed alginate beads.

In the case of oil shale-agar, the crystallizing dishes containing oil shale-agar composite included $5 \mathrm{~g}$ of oil shale powder. The mass of agar layer was identical with the mass of agar content in the oil shale-agar composite.

$50-50 \mathrm{~mL}$ of various initial solute concentrations (2-20 mmol/L for BTEAC or $50 \mu \mathrm{mol} / \mathrm{L}-20 \mathrm{mmol} / \mathrm{L}$ for DIPNS), also containing $0.01 \mathrm{~mol} / \mathrm{L} \mathrm{CaCl}_{2}(\mathrm{pH}=7.6)$, were added to the swollen oil shale powder samples. The Erlenmeyer flasks (oil shale powder, oil shale-alginate and alginate beads) were shaken for $24 \mathrm{~h}$, the crystallizing dishes (agar layer and oil shale-agar composite) were shaken for $48 \mathrm{~h}$ on a horizontal shaker at a rate of 90 cycles per minute for equilibration at room temperature. During each series of experiments, a blank sample was also processed without the solute of BTEAC or DIPNS (the solution included only $0.01 \mathrm{~mol} / \mathrm{L} \mathrm{CaCl}_{2}$ ), conditions of agitation were the same as in the case of the samples containing BTEAC or DIPNS. When equilibrium obtained, $2 \mathrm{~mL}$ of the supernatants were sampled and centrifuged in Eppendorf tubes at 15,000 rpm for $20 \mathrm{~min}$. After the perfect separation, the supernatants were transferred into quartz cuvettes and the absorption spectra were recorded between 200 and $800 \mathrm{~nm}$ at room temperature by a UV/Vis spectrophotometer. The absorbance values of BTEAC or DIPNS were recorded at $\lambda=262$ and $286 \mathrm{~nm}$, respectively. The absorbance value of the blank sample $\left(c_{0}=0 \mathrm{~mol} / \mathrm{L}\right)$ was subtracted. By using calibration curve, concentration was calculated. When the concentration was higher than the upper detection limit of the spectrophotometer, samples were diluted by the supernatant of the blank sample. All samples were in triplicate.

\section{Calculation of concentration and sorption capacity}

The sorbed amount of the solute was calculated by using Eq. (1):

$q_{\mathrm{e}}=\frac{V \cdot\left(c_{0}-c\right)}{m}$,

where $q_{\mathrm{e}}$ is the sorption capacity at equilibrium ( $\mathrm{mol} / \mathrm{g}$ ), $\mathrm{mol}$ of solute adsorbed per gram of adsorbent $(\mathrm{mol} / \mathrm{g}) ; V$ is the volume of the equilibrium solution $(0.05 \mathrm{~L}) ; c_{0}$ and $c$ are the initial and the equilibrium concentrations of the solute $(\mathrm{mol} / \mathrm{L}) ; m$ is the weighed amount of the dry adsorbent $(\mathrm{g})$.

Langmuir or Freundlich adsorption isotherm equations [Eq. (2) or (3), respectively] were used, whichever fitted on the data better, taking the coefficient of determination $\left(R^{2}\right)$ into account (Foo and Hameed 2010). Additionally, rootmean-square error (RMSE) and corrected Akaike information criterion (AICc) models were used to confirm that the selected adsorption isotherm had better fitting to the data than the other one (Glatting et al. 2007). RMSE and AICc were calculated according to Eqs. (S1) and (S2) in the SI.

Langmuir isotherm : $q_{\mathrm{e}}=Q_{\max } \cdot \frac{K_{\mathrm{L}} \cdot c_{\mathrm{e}}}{1+K_{\mathrm{L}} \cdot c_{\mathrm{e}}}$

Freundlich isotherm $: q_{\mathrm{e}}=K_{\mathrm{F}} \cdot c_{\mathrm{e}}^{1 / n}$,

where $q_{\mathrm{e}}$ is the sorption capacity at equilibrium (mol/g); $c_{\mathrm{e}}$ is the equilibrium solute concentration $(\mathrm{mol} / \mathrm{L}) ; Q_{\max }$ is the maximum amount of solute adsorbed for monolayer coverage of the surface $(\mathrm{mol} / \mathrm{g}) ; K_{\mathrm{L}}$ is the Langmuir constant (L/ $\mathrm{mol}) ; K_{\mathrm{F}}\left(\mathrm{L}^{1 / n} /\left(\mathrm{mol}^{((1 / n)-1)} \mathrm{g}\right)\right)$ and $n$ (dimensionless) are Freundlich constants.

In the case of oil shale-alginate beads and oil shale-agar composite, the amount sorbed by oil shale in the composite was computed by deducting the amount sorbed by alginate or agar from the amount sorbed by oil shale-alginate beads or oil shale-agar composite in the following way: after fitting the isotherms to the data, the quantity sorbed by the composite material (oil shale-alginate or oil shale-agar) 
and the binding material (alginate or agar, whose measured sorption values and isotherms are omitted in Figs. 4 and 5) were calculated from the equation of isotherms at the same equilibrium concentration values where the examined composite material was obtained, considering the mass of oil shale composite and the binding material. The differences were attributed to the sorbed quantity of oil shale in the composite. Divided these values by the mass of oil shale, the sorption capacity and equilibrium solute concentration pairs were obtained.

\section{Instruments for characterization of oil shale and prepared composites}

Total organic carbon (TOC) measurement was taken by using a Shimadzu TOC-L analyzer (Kyoto, Japan). Determination of the mineral composition of Hungarian oil shale was conducted on a Philips PW1730 X-ray diffractometer (Almelo, Netherlands) using $\mathrm{Cu}$ radiation $(40 \mathrm{kV}$ and $30 \mathrm{~mA}$ ) and a graphite monochromator, goniometer scanning speed was $2 \%$ min. The crystalline mineral fractions of oil shale were determined by an XDB Powder Diffraction Phase Analytical System 2.7 software. Porosimetric measurements (BET surface area and pore size determinations) were executed on a 3P Instruments BK300C apparatus (Odelzhausen, Germany) using nitrogen gas, bath temperature was $77.35 \mathrm{~K}$. Thermoanalytical measurements were taken with a MOM Derivatograph Q 1500D instrument (Budapest, Hungary). Approximately $700 \mathrm{mg}$ of the sample was weighed in a corundum crucible, and heated from room temperature to $1000{ }^{\circ} \mathrm{C}$ at the rate of $5{ }^{\circ} \mathrm{C} / \mathrm{min}$. Digital microscope images were recorded by using a Keyence VHX2000 device (Osaka, Japan). Scanning Electron Microscope (SEM) analysis was executed on a ThermoFisher (FEI) Apreo S instrument (Brno, Czech Republic) in the secondary-electron mode, used in low vacuum. Samples were dried before the measurements.

\section{Applied analytical methods for the determination of model compounds and used software}

Concentrations of BTEAC and DIPNS were determined by a Varian Cary 50 UV/Vis spectrophotometer (Mulgrave, Victoria, Australia), $\mathrm{pH}$ values were measured by a Radelkis combination $\mathrm{pH}$ electrode (Budapest, Hungary). Critical micelle concentration (CMC) measurements were executed on a First Ten Angstroms FTA1000 pendant drop shape analyzer (Portsmouth, Virginia, USA).

Origin 6.1 scientific graphing and analysis software including nonlinear least-square fitting procedure was used for fitting adsorption isotherms to the data. Diffusion constant calculation software (produced by Gedeon
Table 1 Minerals in the examined oil shale

\begin{tabular}{ll}
\hline Material & $\%(\mathrm{w} / \mathrm{w})^{\mathrm{b}}$ \\
\hline Smectite & 28 \\
Aragonite & 17 \\
Calcite & 12 \\
Mica & 7 \\
Mixed Fe-Mg-carbonates ${ }^{\mathrm{a}}$ & 7 \\
Dolomite & 7 \\
Plagioclase $_{\text {Quartz }}$ & 5 \\
Kaolinite and chlorite & 4 \\
Gypsum & 3 \\
\hline
\end{tabular}

${ }^{\mathrm{a}}$ The peak of siderite mineral was shifted to the direction of the peak of magnesite, which means that mixed $\mathrm{Fe}-\mathrm{Mg}$-carbonates could be found in the sample

${ }^{\mathrm{b}}$ The measurement uncertainty was $\pm 10 \%$, thus, for each mineral, the measured value might deviate from the real one. Therefore, because of the error propagation, higher error arose at the remaining value ( $8 \%$ ). This value can be assigned to the amorphous phase

Table 2 Characterization of the examined oil shale

\begin{tabular}{ll}
\hline Properties & Hungarian oil shale \\
\hline $\mathrm{pH}\left(\right.$ in $0.01 \mathrm{~mol} / \mathrm{L} \mathrm{CaCl}_{2}$ solution) & $7.6 \pm 0.06$ \\
BET surface area $\left(\mathrm{m}^{2} / \mathrm{g}\right)$ & $66.6 \pm 0.21$ \\
Average pore diameter $(\mathrm{nm})$ & $6.38 \pm 0.66$ \\
Main fraction percentage (\%) and its particle & $50.2 \pm 2.22$ \\
size (mm) & $0.2-0.4$ \\
Organic material content $(\%)$ & $13.8 \pm 0.03$ \\
\hline
\end{tabular}

Szádeczky-Kardoss) was written in C++ programming language, using a Dev-C++5.11 compiler.

\section{Results and discussion}

\section{Characterization of the applied Hungarian oil shale}

The identified minerals and their amounts in the used oil shale determined by X-ray diffraction measurements are collected in Table 1. Smectite, aragonite and calcite are the dominant phases, exceeding $50 \%$ of the total content. Smectite is a phyllosilicate, which is responsible for the good swelling capacity of oil shale, aragonite and calcite are carbonate minerals. Among the residual materials, other silicate (mica, plagioclase, quartz, kaolinite, chlorite), carbonate (mixed $\mathrm{Fe}-\mathrm{Mg}$-carbonates, dolomite) and sulfate minerals (gypsum) can be found. The remaining amorphous phase consists mainly of organic components. Further properties of oil shale can be observed in Table 2 . The $\mathrm{pH}$ of oil shale is very close to the neutral value. Its 


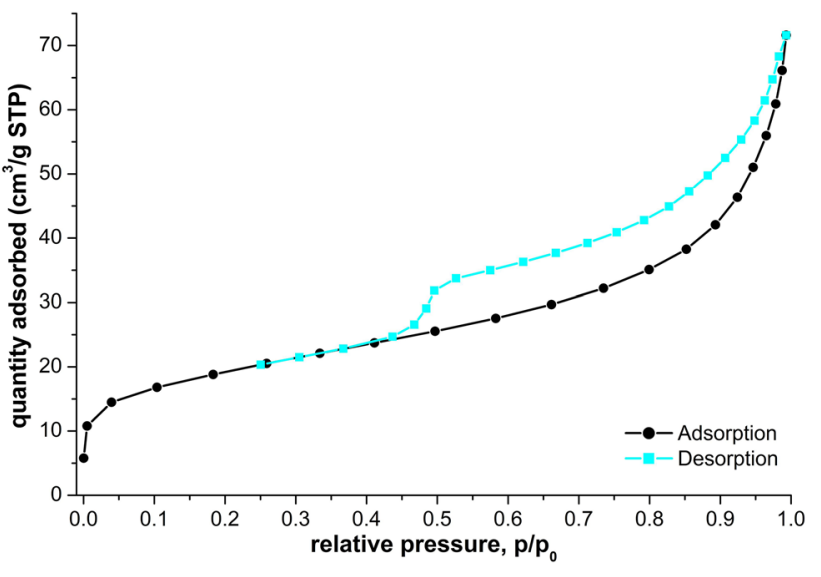

Fig. 1 Nitrogen adsorption and desorption isotherms of the examined oil shale powder at $77 \mathrm{~K}$

specific surface area $\left(66.6 \mathrm{~m}^{2} / \mathrm{g}\right)$ is relatively high compared to other oil shale deposits (Cao et al. 2015); however, the organic material content cannot be called abundant (Hetényi 1996).

The hysteresis loop of low-pressure nitrogen adsorption and desorption isotherms, which can be seen in Fig. 1, exhibits a H3-type hysteresis, according to the IUPAC classification. It is associated with the phenomenon of capillary condensation in the mesopores during the adsorption, capillary evaporation during desorption (Groen et al. 2003; Sang et al. 2018) and mainly slit-shaped pore geometry (Gregg and Sing 1982). This hysteresis loop disappears in the $\mathrm{p} /$ $\mathrm{p}_{0}$ range of $0.4-0.5$, which can be attributed to the tensile strength effect (Groen et al. 2003).

During desorption, the larger pores are emptied first, creating a hysteresis loop. At a critical pressure, the retardation of nitrogen evaporation in the smaller pores $(\varnothing<\sim 4 \mathrm{~nm})$ starts to terminate, the unstable hemispherical meniscus collapses, triggering a sudden exhaustion of pores, which is manifested in a forced closure of the hysteresis loop under the critical pressure. The t-plot method indicated that there was not any detectable microporosity in this sample.

The results of thermal analysis can be seen in Fig. 2. The first endothermic mass loss was between 35 and $221^{\circ} \mathrm{C}$, and corresponds to the elimination of surface-adsorbed, free and interlayer water. The mass loss in this stage was $16.5 \%$. The organic material content started to decay at $221^{\circ} \mathrm{C}$, and kept to about $530{ }^{\circ} \mathrm{C}$. It was manifested in a large, prolonged exothermic peak on the DTA curve. The mass loss in this stage was $11.5 \%$ (13.8\% regarding the sample mass without adsorbed free and interlayer water), which corresponds to the organic material content of the sample. Smectite and illite started to dehydroxylate at $527^{\circ} \mathrm{C}$, and ended at about $607{ }^{\circ} \mathrm{C}$, the mass loss was $4.3 \%$. Finally, an endothermic peak arose between 620 and $890{ }^{\circ} \mathrm{C}$. In this temperature

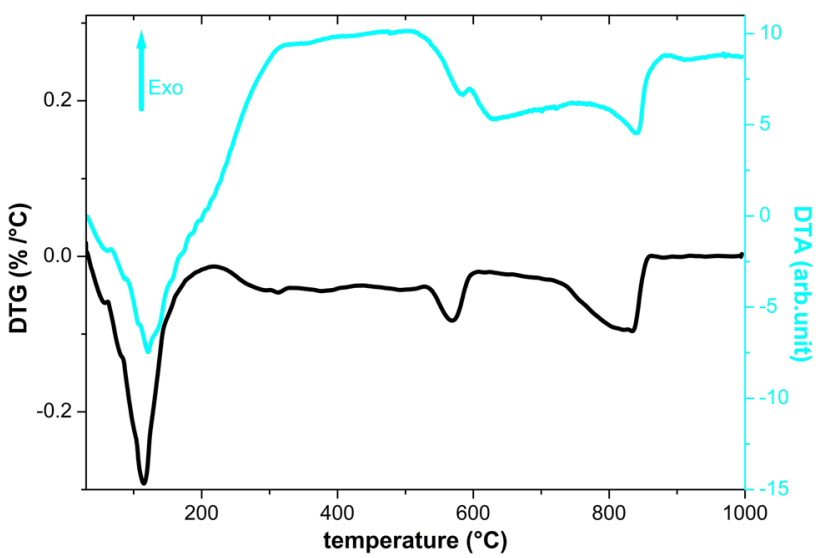

Fig. 2 DTG and DTA curves of Hungarian oil shale powder

range, it can be assigned to the decomposition of carbonate minerals.

\section{Results of sorption experiments}

Figure S2 (in the SI) shows the pictures of the two oil shale composites which were prepared according to the above described methods. Their cross section digital microscope images (Fig. 3a, b); furthermore, SEM images of the dried composite materials (Fig. 3c, d) show the distribution of the oil shale particles in the two composite forms. In the digital microscope images, the distribution of oil shale particles in the oil shale-agar composite (Fig. 3a) seems to be more homogeneous than in the oil shale-alginate composite (Fig. 3b). The particles are in contact with each other in the oil shale-agar, and the agar binding material uniformly surrounds the oil shale. In the oil shale-alginate, however, the distribution of the particles is slightly less uniform. Presumably, this difference arises from the preparation method. When the homogeneous suspension of oil shale-agar was poured into cold dishes, the mixture was rapidly cooled; thus, the oil shale particles could not move, largely because of the arising of fast gelling effect of agar. Conversely, when the homogeneous suspension of oil shale-alginate was dropped into $\mathrm{CaCl}_{2}$ solution, in the inside of the beads, the gelling effect of alginate did not arise immediately because the $\mathrm{CaCl}_{2}$ solution did not penetrate promptly into the middle of the beads; therefore, the oil shale particles had enough time to move slightly.

In the SEM image of intersection of oil shale-agar composite (Fig. 3c), the regular uniformity of the top can be noticed. The specific surface area of this composite is less compared to the oil shale-alginate. Oppositely, the SEM image of oil shale-alginate composite (Fig. 3d) shows a rough surface of the beads, rendering an even higher specific surface area to the beads and faster attainment of sorption 
Fig. 3 Digital microscope image of oil shale-agar (a) and oil shale-alginate (b) composite, SEM image of oil shaleagar (c) and oil shale-alginate (d) composite

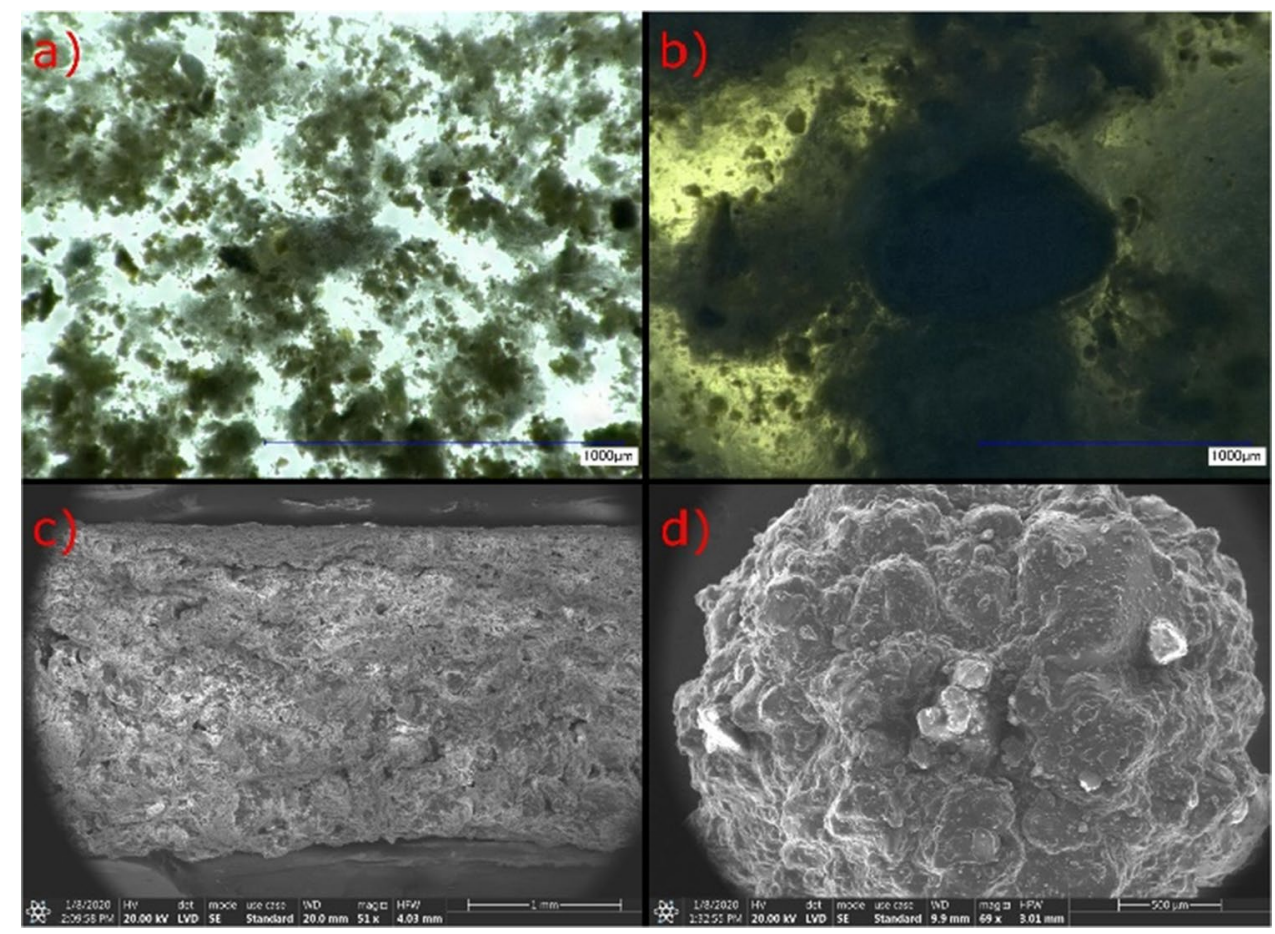

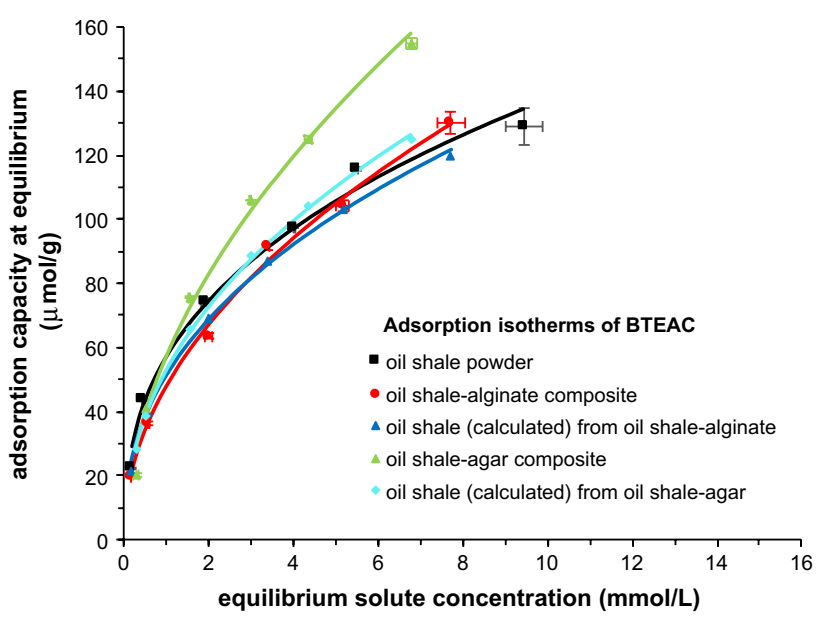

Fig. 4 Adsorption isotherms of BTEAC on oil shale powder, oil shale-alginate and oil shale-agar composites, calculated values of sorption capacity of oil shale in the oil shale-alginate and oil shaleagar composites [all data are described by Freundlich isotherms (Eq. (3))]. Further details about the procedure and conditions of the experiments are given in section "Sorption experiments"

equilibrium. At both composites, the oil shale particles are completely surrounded by the binding materials. Nonetheless, the sorption sites of oil shale in the composite were not covered, the sorption efficiency of oil shale particles was appropriate (results see below).

The adsorption isotherms of cationic BTEAC can be seen in Fig. 4. In the case of oil shale-agar composite, the adsorption isotherm is significantly above that of oil shale powder in the higher concentration range, indicating that agar increased the sorption capacity of the composite.

Additionally, the amount sorbed by oil shale calculated from the oil shale-agar composite well agrees with those of the oil shale powder, so agar did not modify the amounts of BTEAC sorbed by oil shale in this composite. Although agar contains not just neutral, but also negatively charged groups, owing to the agaropectin fraction, the electrostatic interaction did not retard the transport of BTEAC in the composite. On the other hand, in the case of oil shale-alginate composite, the adsorption isotherm is almost identical to that of oil shale powder; furthermore, the amount sorbed by the oil shale calculated from the oil shale-alginate composite is slightly lower than that regarding the oil shale powder. In the oil shale-alginate composite, the transport of cationic BTEAC to the oil shale is hindered through the negatively charged carboxylic acid moieties of alginate because of the electrostatic attraction between the BTEAC and alginate. Therefore, BTEAC was mostly located in the composite. The effect of the binding material on the sorption capacity of the composite was not remarkable in this case, comparing to that of the oil shale powder.

Figure 5 displays the adsorption isotherms of DIPNS on various adsorbents. The arrangement of the adsorption isotherms is different from the case of BTEAC because of the deviating chemical properties of the adsorbates. At both composites, the binding materials increased the sorption capacities of the composite materials compared to that of the oil shale powder, because both adsorption isotherms are largely above that of the oil shale powder. Furthermore, 


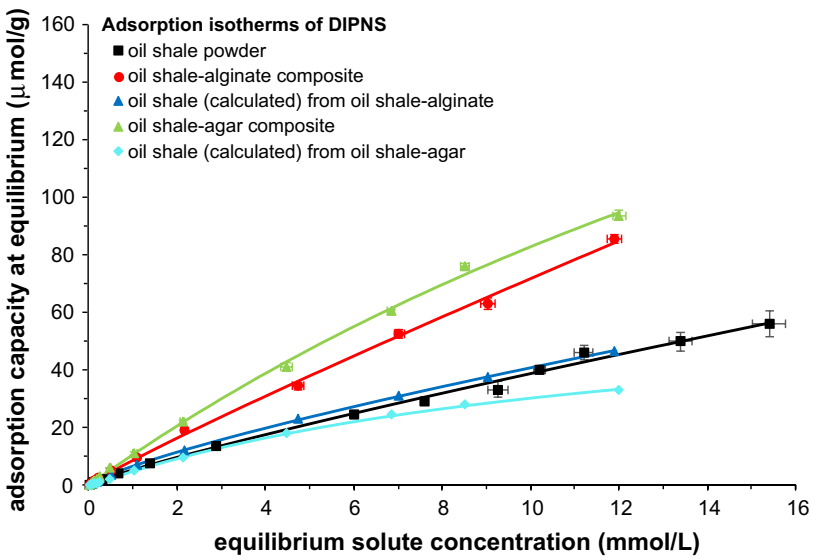

Fig. 5 Adsorption isotherms of DIPNS on oil shale powder [Freundlich isotherm (Eq. (3))], oil shale-alginate (Freundlich isotherm) and oil shale-agar [Langmuir isotherm (Eq. (2))] composites, calculated values of sorption capacity of oil shale in the oil shale-alginate (Freundlich isotherm) and oil shale-agar (Langmuir isotherm) composites. Further details about the procedure and conditions of the experiments are given in section "Sorption experiments"

for DIPNS, a significant hydrophobic interaction emerged between the apolar moieties of the adsorbate and the hydrogel. In the oil shale-agar composite, the oil shale itself adsorbed less amount of solute than oil shale powder did. During the sorption process, this hydrophobic interaction arose between the apolar moieties of anionic DIPNS and the agar hydrogel, which reduced the solute uptake by the oil shale in the composite because the oil shale in it was less accessible for DIPNS. However, the solute uptake was remarkably increased by the oil shale-agar composite, which could be attributed to the high sorption affinity of agar gel to DIPNS. Differently, the oil shale in the oil shale-alginate composite could take up a slightly higher amount of solute than the oil shale powder did, although the effect of the binding material on the sorption enhancement was smaller than in the case of oil shale-agar composite, which could be attributed to the smaller affinity of alginate gel to DIPNS compared to agar gel. These effects of binding material might be assigned to the hydrophobic interaction between the apolar moieties of DIPNS and hydrogels. The reason why the oil shale in the oil shale-alginate composite could take up a moderately higher amount of solute might be a competition of electrostatic and hydrophobic interactions. The electrostatic repulsion between the carboxylic acid moieties of alginate and DIPNS probably marginally overcame the resultant force of hydrophobic interaction between apolar moieties of DIPNS and alginate hydrogel, and electrostatic repulsion between negatively surface-charged oil shale in the composite and DIPNS. Thus, the sorbed DIPNS species were slightly accumulated on the oil shale particles in the composite.

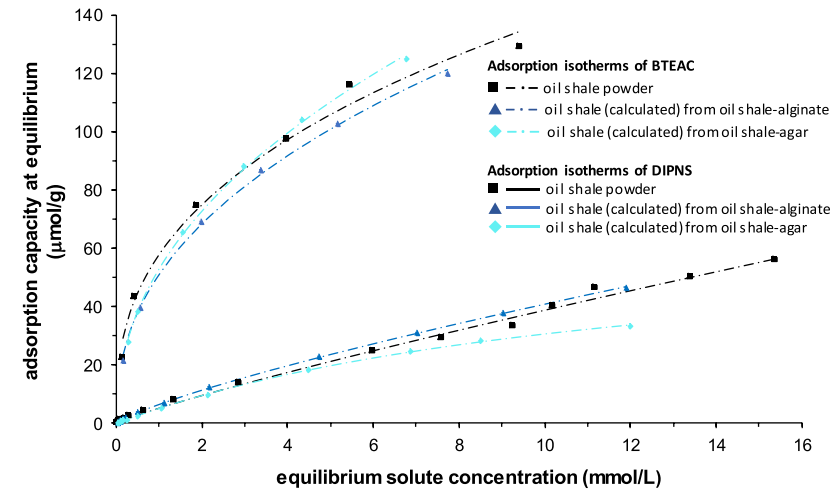

Fig. 6 Comparison of adsorption isotherms of BTEAC and DIPNS on oil shale powder and oil shale calculated from composites

It is worth highlighting that the equilibration time was 2 days in the case of oil shale-agar composite layer, while regarding the oil shale-alginate composite beads and the oil shale powder, it took only 1 day. Presumably, this difference can be attributed to the deviating relative surface areas. It was much smaller for the oil shale-agar composite layer; hence, the rate of the sorption process was slower in this case.

Figure 6 demonstrates the sorption differences between the cationic BTEAC and anionic DIPNS compounds. As it was expected, much higher amount of BTEAC could be sorbed by the negatively surface-charged oil shale in the investigated concentration range because of the electrostatic interaction between oil shale and solutes.

Except for two cases, Freundlich adsorption isotherm proved to be more adequate for fitting to the experimental data than the Langmuir type one. The exception was the DIPNS sorption in the oil shale-agar composite and oil shale calculated from oil shale-agar composite. Although the Langmuir isotherm model assumes monolayer adsorption and homogeneous adsorption surface, and originally this model was devoted to describe gas-solid-phase adsorption (Foo and Hameed 2010), it has been used to describe more complex systems, such as liquid chromatography (Guiochon 2002; Liu et al. 2002), because a good fit alone does not mean that the system studied corresponds to the theory of the model. The calculated parameters of the applied adsorption isotherms can be seen in Table S1. $R^{2}$, RMSE and AICc tests unanimously indicated a better fit of the chosen adsorption isotherm (highlighted) compared to the other model.

Although in most cases Freundlich isotherm had a better fitting than Langmuir isotherm in this work, the differences in $R^{2}$ were not large. Since Freundlich isotherm does not carry any information providing $Q_{\max }$ value $\left(K_{\mathrm{F}}\right.$ of Freundlich isotherm relates to adsorption capacity, but it is impossible to determine $Q_{\max }$ ), Langmuir isotherm was used to estimate the maximum theoretical adsorption 
capacity. Above the concentration of CMC, the quantity of individual surfactant ions are constant in the solution; thus, reaching CMC, adsorption isotherm levels off. Considering the $\mathrm{CMC}$ values of the model pollutants in solutions of applied composition $\left(0.01 \mathrm{~mol} / \mathrm{L} \mathrm{CaCl}_{2}\right.$ and given concentration of organic material released from oil shale (for results see below)), $Q_{\max }$ values have to be modified accordingly. Table $\mathrm{S} 2$ represents the calculated values of $Q_{\max }$ of DIPNS from Langmuir adsorption isotherm equations, taking CMC into consideration. BTEAC reaches CMC above $150 \mathrm{mmol} / \mathrm{L}$. In this high concentration region, the sorption capacity $\left(q_{\mathrm{e}}\right)$ is approximately equal to $Q_{\max }$. Thus, in this case, correction is unnecessary.

Analyzing the $\mathrm{K}_{\mathrm{L}}$ values of Langmuir isotherm in Table S1, which is related to the energy of adsorption, approximately an order of magnitude larger values were obtained in the case of BTEAC compared to DIPNS. The $n$ parameter from $1 / n$ of Freundlich isotherm carries an analogous meaning, which indicates the adsorption intensity. These $n$ values are also higher for BTEAC (1.90-2.66) than those for DIPNS (1.09-1.38), which indicates a more favorable sorption process for BTEAC (Hamdaoui and Naffrechoux 2007).

In Table 3, maximum sorption capacities $\left(Q_{\max }\right)$ calculated from Langmuir isotherms are compared to the data obtained by other authors for different oil shales, alginate- or agar-based composites. As it can be seen, oil shale-alginate and oil shale-agar composites presented in this work are comparable to other alginate or agar-based composites. Composite materials listed in Table 3 usually have higher $Q_{\max }$ value compared to that of oil shale powder; thus, these materials can more effectively remove contaminants. Since Hungarian oil shale is an extremely low-cost component, oil shale-alginate and oil shale-agar materials have a considerable potential in usage as sorbent of pollutants.

\section{Results of TOC measurements}

The TOC results regarding the organic material released from oil shale to the supernatant show considerable differences between oil shale powder, oil shale-alginate and oil shale-agar composites. Comparing the data in Table 4, the

Table 3 Comparison of maximum sorption capacities $\left(Q_{\max }\right)$ of oil shale-, alginate- or agar-based sorbents

\begin{tabular}{|c|c|c|c|c|}
\hline \multirow[t]{2}{*}{ Sorbent } & \multirow[t]{2}{*}{ Solute } & \multicolumn{2}{|l|}{$Q_{\max }$} & \multirow[t]{2}{*}{ References } \\
\hline & & $(\mu \mathrm{mol} / \mathrm{g})$ & $(\mathrm{mg} / \mathrm{g})$ & \\
\hline \multirow[t]{2}{*}{ Hungarian oil shale } & BTEAC & $140 \pm 11.1$ & $31.9 \pm 2.53$ & \multirow[t]{6}{*}{ This work } \\
\hline & DIPNS & $81.5 \pm 2.6$ & $25.6 \pm 0.82$ & \\
\hline \multirow[t]{2}{*}{ Oil shale-alginate } & BTEAC & $171 \pm 22.8$ & $38.9 \pm 5.19$ & \\
\hline & DIPNS & $165 \pm 7.6$ & $51.9 \pm 2.39$ & \\
\hline \multirow[t]{2}{*}{ Oil shale-agar } & BTEAC & $208 \pm 15.6$ & $47.4 \pm 3.55$ & \\
\hline & DIPNS & $151 \pm 1.6$ & $47.5 \pm 0.50$ & \\
\hline \multirow[t]{4}{*}{ Turkish oil shale } & 2,4-dichlorophenoxyacetic acid & 8.78 & 1.94 & Ayar et al. (2008) \\
\hline & Thionine & 103 & 23.5 & \multirow[t]{3}{*}{ Acar et al. (2015) } \\
\hline & Toluidine blue & 40 & 10.8 & \\
\hline & Methylene blue & 25 & 8.00 & \\
\hline \multirow[t]{3}{*}{ Malaysian oil shale } & Triton X-100 & 6.21 & 4.02 & \multirow[t]{3}{*}{ Yekeen et al. (2019) } \\
\hline & Cetyltrimethylammonium bromid & 45.5 & 16.6 & \\
\hline & Sodium dodecylbenzenesulfonate & 5.71 & 1.99 & \\
\hline \multirow[t]{3}{*}{ Poly( $N$-vinyl-2-pyrrolidone)-alginate } & Reactive red 120 & 79.5 & 116.8 & \multirow[t]{3}{*}{ İnal and Erduran (2015) } \\
\hline & Cibacron brilliant red 3B-A & 73.3 & 73.3 & \\
\hline & Remazol brilliant blue $\mathrm{R}$ & 88.3 & 55.3 & \\
\hline Montmorillonite-alginate & Basic red 46 & 88.0 & 35.3 & Hassani et al. (2015) \\
\hline $\begin{array}{l}\text { Zeolite-activated carbon-layered double hydrox- } \\
\text { ides-magnetic nanoparticles-xanthan gum-algi- } \\
\text { nate }\end{array}$ & Toluene & 277 & 25.5 & Phiri et al. (2019) \\
\hline \multirow[t]{2}{*}{ Activated bentonite-alginate } & Methylene blue & $1294 \pm 28$ & $414 \pm 9$ & \multirow[t]{2}{*}{ Belhouchat et al. (2017) } \\
\hline & Methyl orange & $354 \pm 37.6$ & $116 \pm 12.3$ & \\
\hline Clinoptilolite-alginate & Methylene blue & 1413 & 452 & Dinu et al. (2017) \\
\hline Graphene oxide-agar & Methylene blue & 1807 & 578 & Chen et al. (2017) \\
\hline к-Carrageenan-agar & Methylene blue & 757 & 242 & Duman et al. (2020) \\
\hline
\end{tabular}

Values of standard deviation are indicated where these pieces of information are available 
Table 4 TOC released into the supernatant during the sorption experiments

\begin{tabular}{llr}
\hline Adsorbent & $\begin{array}{l}\text { Incubation time } \\
(\mathrm{h})\end{array}$ & TOC (mg/L) \\
\hline Oil shale powder & 24 & $135.8 \pm 1.56$ \\
& 48 & $141.7 \pm 1.29$ \\
Oil shale-alginate composite & 24 & $21.5 \pm 1.48$ \\
& 48 & $29.5 \pm 1.21$ \\
Oil shale-agar composite & 24 & $110.5 \pm 1.32$ \\
& 48 & $137.9 \pm 1.58$ \\
\hline
\end{tabular}

reduced amount of organic material released to the supernatant could be observed in the case of the two composites compared to the oil shale powder as a reference base. The oil shale-alginate composite could reduce this released organic material to the greatest extent after $24 \mathrm{~h}$, the decrease was higher than $84 \%$. For the sake of comparability of the results, samples were taken after 24 and $48 \mathrm{~h}$ uniformly, although the incubation time was $48 \mathrm{~h}$ only in the case of oil shale-agar composite. In this event, the decrease in released organic material was minor, it was $2.7 \%$ after $48 \mathrm{~h}$, (this rate was $18.6 \%$ after $24 \mathrm{~h}$ ). Since the release of organic material is a process leading to equilibrium, its rates were not consistent, in all cases higher amount was released in the first 24-h period than in the second one because the driving force decreased over time. These results confirm that both oil shale-alginate and oil shale-agar composites can decrease the amount of organic material released from the oil shale, however, this effect arose to a higher extent at the oil shale-alginate composite.

The organic material released from oil shale usually increases the solubility of organic pollutant in the supernatant (Rauch and Földényi 2020), interaction might emerge between organic material and pollutant in the liquid phase, which could decrease the sorption of solute. Furthermore, in the case of surfactant pollutant, the released organic material decreases its $\mathrm{CMC}$ value; thus, the removal can be less effective in a higher concentration range (adsorption isotherm levels off). However, in practice, wastewaters in which the concentrations of surfactant pollutants exceed their CMC values is rare. It is not advisable to remove the organic material from oil shale before application because it would represent additional cost, and the effect of the released organic material on the sorption of surfactant solute might be negligible below CMC. Nonetheless, in the case of oil shale composites, the reduced amount of organic material released into the supernatant could aid the sorption of solute.

\section{Calculation of diffusion coefficients}

\section{Description and calculation of diffusion into oil shale- alginate beads}

The goal was to determine the diffusion coefficient $(D)$, which defines the rate of diffusion of solutes in the oil shale-alginate beads. These spheres are immersed in a limited volume of solution; hence, the concentration of solute changes in the solution, when the solute diffuses into the beads. The diffused amount can be easier determined by calculation from the decrease in the concentration of solute in the supernatant, than by direct measurement of the amount of solute in the solid phase (Tanaka et al. 1984). In the case of a well-stirred solution, the concentration of solute in the solution, $C_{\mathrm{L}}{ }^{\mathrm{D}}(t)$, depends on $D$, the time elapsed from the beginning of experiment $(t)$, the radius of oil shale-alginate beads $(a)$, the initial and the equilibrium concentration of solute in the solution ( $C_{\mathrm{LO}}$ and $C_{\mathrm{LE}}$, respectively).

The model was the following: $V_{\mathrm{g}}$ is the total volume of the sorbent spheres with an identical radius $(a)$. These spheres sink into a finite volume of solution $(V)$, and their entire surface area is surrounded by the solution. Initially, the spheres are free of the solute. During the sorption process, the concentration of solute in the entire liquid phase is homogeneous. The initially adjusted concentration in the solution, $C_{\mathrm{LO}}\left[=C_{\mathrm{L}}^{\mathrm{D}}(0)\right]$ at the start of experiment finally decreases to $C_{\mathrm{LE}}\left[=\lim _{t \rightarrow \infty} C_{\mathrm{L}}^{\mathrm{D}}(t)\right]$. By this time, the concentration of solute in the spheres is spatially homogeneous, too, but not necessarily identical with $C_{L E}$, but with its $K$-fold value. This rate defines the directly immeasurable $K$ number. Within the surface of the spheres-except at the $t=0$ moment-the concentration is always $(t>0) K$-fold of those of solution: $K \cdot C_{\mathrm{L}}{ }^{\mathrm{D}}(t)$. From the $t=0$ time, the following Fick equation [Eq. (4)] describes the diffusion process with a time- and concentration-independent diffusion coefficient (if $D$ depends on temperature, constant temperature is required).

$\frac{\partial C(x, y, z, t)}{\partial t}=\operatorname{div}(D \cdot \operatorname{grad} C(x, y, z, t))$,

where $C(x, y, z, t)$ is time- and place-dependent concentration of solute in the spheres. This diffusion process dissolves the solute penetrated into the spheres. In the case of fulfillment of these conditions, and knowing $C_{\mathrm{LO}}, C_{\mathrm{LE}}, a$ and $D$ (in fact, $D / a^{2}$ relation is sufficient to know), $C_{\mathrm{L}}{ }^{\mathrm{D}}(t)$ function can be unequivocally determined.

The rate between affinities of the solute to the solvent and to the spheres of composite material defines the specific $K$ constant. The material balance equation [Eq. (5)] was utilized to calculate its value: 
$K=\frac{V \cdot\left(C_{\mathrm{LO}}-C_{\mathrm{LE}}\right)}{V_{\mathrm{g}} \cdot C_{\mathrm{LE}}}$.

The concentration of the liquid phase was measured at various times elapsed from the beginning of the experiment, $\quad 0<t_{1}<t_{2}<t_{3}<\cdots<t_{N-3}<t_{N-2}<t_{N-1}$, obtaining the $C_{1}, C_{2}, C_{3}, \ldots, C_{N-3}, C_{N-2}, C_{N-1}$ values. Having added $C_{0}, C_{0} \stackrel{\text { def }}{=} C_{\mathrm{LO}}$, to these data, an $N$-pieces database was created. (Theoretically, one of these $C(t>0)$ data could be sufficient for computing $D$; however, in reality the conditions can just approximate those of the model, and the measurements had a standard deviation. Thus, all concentration values ( $N$ pieces) were applied for the calculation of the diffusion coefficient). The value of $D$ was calculated by the least-square method using the sum of $\sum_{i=0}^{N-1}\left(C_{\mathrm{L}}^{\mathrm{D}}\left(t_{i}\right)-C_{i}\right)^{2}$. Accordingly, the concentration of solute in the liquid phase can be expressed by the following infinite row [Eq. (6)], and this equation was applied in the description of kinetic data, when oil shale-alginate beads were immersed into a solution containing BTEAC or DIPNS (and $0.01 \mathrm{~mol} / \mathrm{L} \mathrm{CaCl}_{2}$ ):

$C_{\mathrm{L}}^{\mathrm{D}}(t)=C_{\mathrm{LE}} \cdot\left[1+6 \cdot(\alpha+1) \cdot \sum_{n=1}^{\infty}\left(\frac{\exp \left(-q_{n}^{2} \cdot D \cdot t \cdot a^{-2}\right)}{9 \cdot \alpha+9+q_{n}^{2} \cdot \alpha^{2}}\right)\right]$,

where $q_{n}$ is a nonzero positive root of $\tan \left(q_{n}\right)=\frac{3 \cdot q_{n}}{\alpha \cdot q_{n}^{2}+3}$, $0<q_{1}<q_{2}<q_{3} \ldots<q_{n}$. Furthermore, $\alpha=\frac{C_{\mathrm{LE}}}{C_{\mathrm{LO}}-C_{\mathrm{LE}}}(\mathrm{Crank}$ 1975; Tanaka et al. 1984), which is formally different from the definition in the references, but has the same numerical value. The $q_{n}$ roots were calculated with a 14-digit accuracy, and the first 100 terms of $q_{n}$ were considered during the $C_{\mathrm{L}}{ }^{\mathrm{D}}(t)$ evaluation. The calculations were resolved with 18-digit decimal number accuracy.

The highest initial concentration $(20 \mathrm{mmol} / \mathrm{L})$ was selected for both chemicals (BTEAC and DIPNS), and the decrease in their concentration was monitored periodically. Thus, $C_{1}, C_{2}, C_{3}, \ldots, C_{N-3}, C_{N-2}, C_{N-1}$ data series were obtained for each solute. Accordingly, the calculated diffusion coefficients were $1.58 \times 10^{-5}$ and $2.07 \times 10^{-5} \mathrm{~cm}^{2} /$ $\min$ in the case of BTEAC and DIPNS, respectively. The calculated and the experimental values are displayed in Fig. 7, and listed in Tables S3 and S4. Although DIPNS has higher molecular weight, its diffusion coefficient was higher than that of the lower molecular weight BTEAC. At first, these results could be a contradiction, but considering the features of the system, this behavior is reasonable. The key effect was the electrostatic interaction between the negatively charged oil shale-alginate composite and the cationic BTEAC or anionic DIPNS. The electrostatic attraction between BTEAC and the carboxylic acid moieties of alginate and the negatively surfacecharged oil shale in the composite retarded the transport

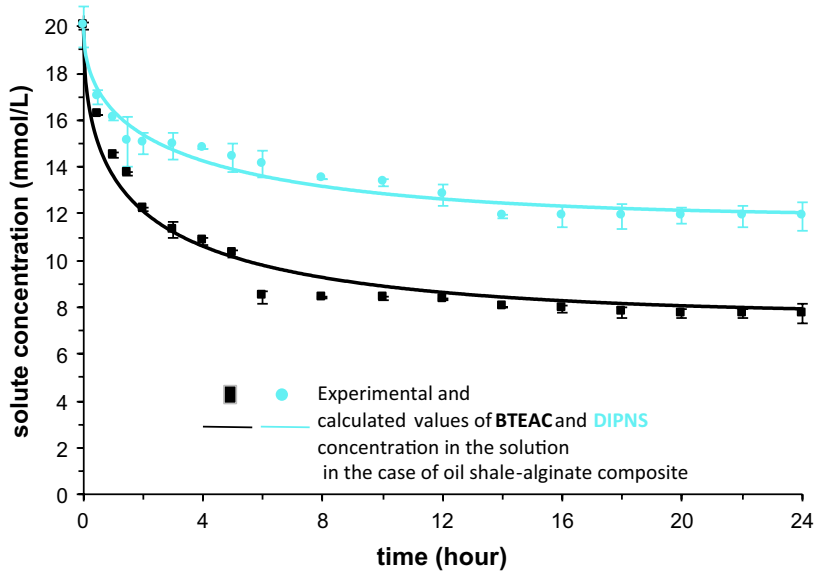

Fig. 7 Experimental and calculated concentration values of supernatant of BTEAC and DIPNS as functions of time, when oil shalealginate beads were immersed into a solution containing BTEAC or DIPNS (initial concentration: $20 \mathrm{mmol} / \mathrm{L}$ ) and $0.01 \mathrm{~mol} / \mathrm{L} \mathrm{CaCl}_{2}$

of BTEAC in the gel, resulted in a lower diffusion coefficient. Differently, electrostatic repulsion arose between oil shale in the composite or alginate and DIPNS, which rendered an excess of driving force; hence, a higher diffusion coefficient was obtained. These results correspond to the explanation described in section "Results of sorption experiments."

\section{Description and calculation of diffusion into oil shale-agar layer}

The shape of oil shale-agar composite sorbent was considered as a right circular cylinder. Except for the shape of sorbent and the incubation time ( 2 days in this case), other circumstances were unvaried compared to the oil shale-alginate beads. Hence, during the description of this model, the nomenclature used in section "Description and calculation of diffusion into oil shale-alginate beads" was kept, and the deviation of differently shaped sorbent was highlighted.

The model was the following: $V_{g}$ is the volume of a rightcircular-cylinder shape sorbent, which was immersed in $V$ volume of solution in such a way that from the horizontally located bases, the upper one contacted with its whole surface with the solution, while the lower one and the lateral surface of the cylinder were perfectly isolated from the solution; thus, diffusion did not take place through these surfaces. The height of the cylinder is $L$. Under these circumstances, the time-dependence of the concentration of solute in the liquid phase, $C_{\mathrm{L}}{ }^{\mathrm{D}}(t)$, can be theoretically determined.

The shape of the sorbent and its determinative size $\left(V_{\mathrm{g}}\right.$ and $L$ ) influence the rate of the sorption of solute, and therefore, the calculation method of $C_{\mathrm{L}}{ }^{\mathrm{D}}(\mathrm{t})$ [Eq. (7)]: 
$C_{\mathrm{L}}^{\mathrm{D}}(t)=C_{\mathrm{LE}} \cdot\left[1+2 \cdot(\alpha+1) \cdot \sum_{n=1}^{\infty}\left(\frac{\exp \left(-p_{n}^{2} \cdot D \cdot t \cdot L^{-2}\right)}{1+\alpha+p_{n}^{2} \cdot \alpha^{2}}\right)\right]$,

where $p_{n}$ is a nonzero positive root of $\tan \left(p_{n}\right)=-\alpha \cdot p_{n}$ , $0<p_{1}<p_{2}<p_{3} \cdots<p_{n}$. Calculation accuracy of $p_{n}$ roots was the same as that of $q_{n}$ roots in section "Description and calculation of diffusion into oil shale-alginate beads." Furthermore, Eq. (7) was applied in the description of kinetic data, when a solution containing BTEAC or DIPNS (and $0.01 \mathrm{~mol} / \mathrm{L} \mathrm{CaCl}_{2}$ ) was poured onto oil shale-agar layer. This result is the consequence of Eq. (8) (Crank 1975):

$\frac{M_{t}}{M_{\infty}}=1-2 \cdot \alpha \cdot(\alpha+1) \cdot \sum_{n=1}^{\infty}\left(\frac{\exp \left(-p_{n}^{2} \cdot D \cdot t \cdot L^{-2}\right)}{1+\alpha+p_{n}^{2} \cdot \alpha^{2}}\right)$,

where $M_{t}$ and $M_{\infty}$ are the amount of solute sorbed by the sorbent during the elapsed time, $t$, and at equilibrium, respectively.

The calculated diffusion coefficients were $4.29 \times 10^{-5}$ and $8.66 \times 10^{-5} \mathrm{~cm}^{2} / \mathrm{min}$ in the case of BTEAC and DIPNS, respectively. The calculated and the experimental values are displayed in Fig. 8, and listed in Tables S5 and S6. The same trend can be observed regarding the two ionic compounds, compared to the oil shale-alginate composite. In the oil shale-agar composite, in which agar is not significantly charged, electrostatic interaction between the negatively charged surface of the oil shale in the composite and the solute was the dominant one. This interaction defined the transport rate of solute, although, as it was mentioned in section "Results of sorption experiments," hydrophobic interaction arose between DIPNS and agar hydrogel as well. Attractive electrostatic interaction (between BTEAC and oil

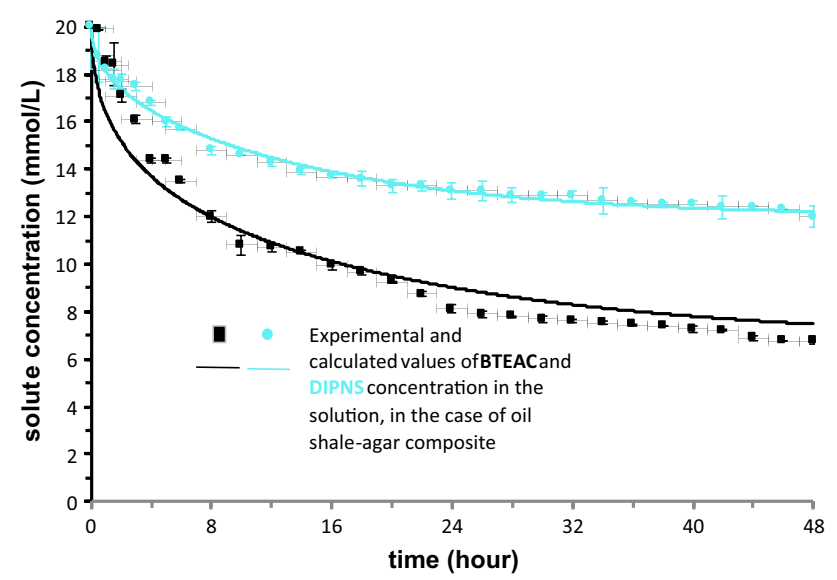

Fig. 8 Experimental and calculated concentration values of supernatant of BTEAC and DIPNS as functions of time, when a solution containing BTEAC or DIPNS (initial concentration: $20 \mathrm{mmol} / \mathrm{L}$ ) and $0.01 \mathrm{~mol} / \mathrm{L} \mathrm{CaCl}_{2}$ was poured onto oil shale-agar composite shale) decelerated, while repulsive electrostatic interaction (between DIPNS and oil shale) accelerated the transport of solute in the composite.

During the sorption experiments, homogeneity of liquid phase was provided by agitation of the Erlenmeyer flasks and crystallizing dishes on a horizontal shaker. In this way, the diffusion of solute molecules (BTEAC or DIPNS) through the solution onto the surface of the sorbent (oil shale-alginate or oil shale-agar composite) could be ignored. The second stage was the sorption of solute molecules onto the external layer of hydrogel composites, as the oil shale particles completely surrounded by the binding materials, which was concluded from the SEM images. In this phase, between the solute and the composite material, the attractive forces increased, and the repulsive forces decreased the efficiency of this process. Thus, the attractive forces between BTEAC and the carboxylic acid moieties of alginate hydrogel increased, while the repulsive forces between the alginate and DIPNS decreased the sorption onto the external layer of hydrogel. In the case of the not-significantly charged agar hydrogel, presumably there was not any relevant electrostatic interaction between agar and the two ionic solute molecules. The final stage of the sorption process was the diffusion of solute from the external layer to the inside of composite material. The interactions between the sorbent and the solute have been detailed above. As this last stage was the rate-determining step of sorption; thus, these interactions determined the rate of sorption.

As Figs. 7 and 8 demonstrate, at the beginning of the experiment, the concentration decrease in solute in the supernatant was greater than at the end of the sorption process. The driving force of sorption was the gradient between the concentration of solute in the supernatant and in the composite material; thus, during the equalization of concentration of solute in the two phases, the degree of concentration decrease in solute in the supernatant reduced.

The difference in the calculated diffusion coefficients of solute in the oil shale-alginate and oil shale-agar composite was caused merely by the diversity of the composite materials. Even the alteration of the shape of composites would not have changed the diffusion coefficient. In the oil shale-agar composite, diffusion coefficients of both ionic compounds were higher than those of in the oil shale-alginate composite.

\section{Regeneration and reusability of sorbents}

After the sorption of solute (initial concentration of BTEAC or DIPNS: $20 \mathrm{mmol} / \mathrm{L}$, also containing $0.01 \mathrm{~mol} / \mathrm{L}$ $\mathrm{CaCl}_{2}$ ), regenerations of sorbents were performed by using $0.01 \mathrm{~mol} / \mathrm{L} \mathrm{CaCl}_{2}$ solution. The time and circumstances of the desorption process were similar to that of the sorption. Before the resorption of solute $(20 \mathrm{mmol} / \mathrm{L}$ in $0.01 \mathrm{~mol} / \mathrm{L}$ 
$\mathrm{CaCl}_{2}$ solution), the desorption procedure was repeated twice.

The results were different for BTEAC and DIPNS. Table S7 (in the SI) shows the obtained sorption capacity before and after regeneration of sorbents. Resorption of BTEAC on oil shale powder, shale-alginate or shale-agar was of lesser extent compared to the first usage of the sorbents $(69,79$ or $85 \%$, respectively). In contrast, resorption of DIPNS on the regenerated sorbent was almost as efficient as the sorption on the original ones $(93,96$ or $98 \%)$. Nonetheless, the tendencies were similar. Oil shale powder could be regenerated to the smallest extent, while shale-agar could be regenerated to the highest extent for both chemicals. The fact that DIPNS was desorbed almost completely from the sorbents indicates weaker interactions between the solute and the sorbents compared to the case of BTEAC.

Regeneration of sorbent is a cost-efficient option, it can reduce the waste amount, and, if it is necessary, it can recovery pollutants, too.

\section{Potential for application of oil shale and oil shale composites as sorbent}

Wastewaters containing pollutants in dissolved form can be purified in industrial size, using these sorbents as well. Oil shale powder can be utilized in fixed-bed or batch reactor. In this case, fixed-bed reactor might be more problematic than batch reactor. If the particle size of oil shale powder was too small, the pressure drop in column would be too high, and it would easily lead to clogging. At a higher-particlesize fraction of oil shale powder, fixed-bed reactor could be utilized in continuous operation at an optimum flow rate, which could be determined by upscale studies. Batch reactor containing oil shale powder would be a simpler solution. For a better efficiency, the material flow of solute should be supported by agitation. At the end of both processes, settling or filtration of the suspension should be applied in order to separate the oil shale powder and the liquid phase.

Oil shale-alginate beads can be used in both batch and fixed-bed reactors. In a fixed-bed reactor, during the production of composite beads, an optimum diameter, furthermore, an optimum flow rate should be chosen, in which case the separation efficiency is high. It requires preliminary studies dealing with upscale.

Oil shale-agar could be primarily utilized in batch reactor. Composite material on a support can be placed in the reactor in multiple rows horizontally or vertically, in order to enhance the surface of sorbent. In this way, the efficient separation can be achieved upon stirring the solution.

For both composite materials, filtration or settling is an unnecessary step in the process, because no solid particles enter into the liquid phase during the separation.
Consideration is needed in order to find the most suitable sorbent which meets the requirements. As oil shale is the cheapest component of both composites, its price is approximately 17.3 USD/ton, binding materials increase the price of the composite sorbents (one of the cheapest sodium alginate and agar are 900 and 1000 USD/ton, respectively) but they increase the removal efficiency as well. The most proper sorbent can be selected after a deliberation which characteristics are important from the following ones: high removal efficiency, fast removal, cheap removal of solute, which type of reactor is preferred, filtration or settling process should be omitted or not, organic material released from oil shale to the liquid phase is unwanted or irrelevant.

\section{Conclusion}

In this study, using alginate or agar natural binding materials, two composite forms containing oil shale were prepared, and sorption properties of two ionic compounds on these composites and oil shale powder were measured and compared. An explanation was provided, according to which electrostatic and hydrophobic interactions between the binding material and the solute modify the accessibility of the oil shale in the composite. Furthermore, in the composite materials, the oil shale functioned as a proper adsorbent as well. Both oil shale-alginate and oil shale-agar composites removed the utilized model pollutants from the liquid phase more efficiently than oil shale powder did in the investigated concentration range. Furthermore, these composites-especially oil shale-alginate-reduced the amount of organic material released from oil shale to the supernatant. Moreover, this reduced amount of organic material could promote the sorption process. The negatively surface-charged oil shale powder and oil shale composites could remove much higher quantity of the cationic (BTEAC) chemical compared to that of the anionic compound (DIPNS) in the investigated concentration range. Additionally, diffusion models of the two composites with diverse shapes (spherical and cylindrical) were described, and the corresponding diffusion coefficients were calculated. From these results, it is suggested that the electrostatic interaction between ionic solute and alginate or oil shale defined the transport rate of solute, rendering a higher diffusion coefficient to the higher molecular weight DIPNS. These composite materials can be utilized as cost-effective sorbents for pollutant removal not just in batch sorption systems, but also in fixed-bed columns. In addition, the right composite material can be selected, depending on the nature of the pollutant. In the future, we will expand the range of compounds with more diverse chemical properties to be examined on these composites. 
Acknowledgments The authors acknowledge the competent help of Gedeon Szádeczky-Kardoss in the calculation and programming, Prof. Dr. Etelka Tombácz and Dr. Zsolt Valicsek. This work was supported by the Széchenyi 2020 under the GINOP-2.3.2-15-2016-00016.

Author contributions R. Földényi contributed to conceptualization; M. Molnár curated the data, helped in investigation and contributed to visualization and writing —original draft; R. Földényi and $\mathrm{O}$. Horváth acquired funding, administered the project and contributed to supervision; O. Horváth contributed to writing—review and editing.

Funding Open access funding provided by University of Pannonia. This work was supported by the Széchenyi 2020 under the GINOP-2.3.2-15-2016-00016.

Availability of data and materials Data are available upon request to the corresponding author.

Code availability Diffusion constant calculation software is available upon request to the corresponding author.

\section{Compliance with ethical standards}

Conflict of interest The authors declare that they have no conflict of interest.

Ethical approval This article does not contain any studies with human participants or animals performed by any of the authors.

Open Access This article is licensed under a Creative Commons Attribution 4.0 International License, which permits use, sharing, adaptation, distribution and reproduction in any medium or format, as long as you give appropriate credit to the original author(s) and the source, provide a link to the Creative Commons licence, and indicate if changes were made. The images or other third party material in this article are included in the article's Creative Commons licence, unless indicated otherwise in a credit line to the material. If material is not included in the article's Creative Commons licence and your intended use is not permitted by statutory regulation or exceeds the permitted use, you will need to obtain permission directly from the copyright holder. To view a copy of this licence, visit http://creativecommons.org/licenses/by/4.0/.

\section{References}

Acar ET, Ortaboy S, Atun G (2015) Adsorptive removal of thiazine dyes from aqueous solutions by oil shale and its oil processing residues: characterization, equilibrium, kinetics and modeling studies. Chem Eng J 276:340-348. https://doi.org/10.1016/j. cej.2015.04.089

Asgari S, Jahanshahi M, Rahimpour A (2014) Cost-effective nanoporous Agar-Agar polymer/Nickel powder composite particle for effective bio-products adsorption by expanded bed chromatography. J Chromatogr A 1361:191-202. https://doi.org/10.1016/j. chroma.2014.08.016

Ayar N, Bilgin B, Atun G (2008) Kinetics and equilibrium studies of the herbicide 2,4-dichlorophenoxyacetic acid adsorption on bituminous shale. Chem Eng J 138:239-248. https://doi.org/10.1016/j. cej.2007.06.032

Belhouchat N, Zaghouane-Boudiaf H, Viseras C (2017) Removal of anionic and cationic dyes from aqueous solution with activated organo-bentonite/sodium alginate encapsulated beads. Appl Clay Sci 135:9-15. https://doi.org/10.1016/j.clay.2016.08.031

Blandino A, Macías M, Cantero D (2001) Immobilization of glucose oxidase within calcium alginate gel capsules. Process Biochem 36:601-606. https://doi.org/10.1016/S0032-9592(00)00240-5

Burns RL, Duliba EP (2000) Hydrotropic and surfactant properties of novel diisopropyl naphthalene sulfonates. J Surfactants Deterg 3:361-368. https://doi.org/10.1007/s11743-000-0140-1

Cao T, Song Z, Wang S, Xia J (2015) A comparative study of the specific surface area and pore structure of different shales and their kerogens. Sci China Earth Sci 58:510-522. https://doi. org/10.1007/s11430-014-5021-2

Chen L, Li Y, Du Q, Wang Z, Xia Y, Yedinak E, Lou J, Ci L (2017) High performance agar/graphene oxide composite aerogel for methylene blue removal. Carbohydr Polym 155:345-353. https ://doi.org/10.1016/j.carbpol.2016.08.047

Crank J (1975) The mathematics of diffusion, 2nd edn. Clarendon Press, Oxford, pp 44-103

de Vos P, Lazarjani HA, Poncelet D, Faas MM (2014) Polymers in cell encapsulation from an enveloped cell perspective. Adv Drug Deliv Rev 67-68:15-34. https://doi.org/10.1016/j.addr.2013.11.005

Dinu MV, Lazar MM, Dragan ES (2017) Dual ionic cross-linked alginate/clinoptilolite composite microbeads with improved stability and enhanced sorption properties for methylene blue. React Funct Polym 116:31-40. https://doi.org/10.1016/j.reactfunct polym.2017.05.001

Duman O, Polat TG, Diker CÖ, Tunç S (2020) Agar/א-carrageenan composite hydrogel adsorbent for the removal of methylene blue from water. Int J Biol Macromol 160:823-835. https://doi. org/10.1016/j.ijbiomac.2020.05.191

Entezari MH, Shameli AA (2000) Phase-transfer catalysis and ultrasonic waves I. Cannizzaro reaction. Ultrason Sonochem 7:169172. https://doi.org/10.1016/S1350-4177(00)00037-7

Foo KY, Hameed BH (2010) Insights into the modeling of adsorption isotherm systems. Chem Eng J 156:2-10. https://doi. org/10.1016/j.cej.2009.09.013

Glatting G, Kletting P, Reske SN, Hohl K, Ring C (2007) Choosing the optimal fit function: comparison of the Akaike information criterion and the F-test. Med Phys 34:4285-4292. https://doi. org/10.1118/1.2794176 
Gregg SJ, Sing KSW (1982) Adsorption, surface area and porosity, 2nd edn. Academic Press, London, pp 126-132

Groen JC, Peffer LAA, Pérez-Ramírez J (2003) Pore size determination in modified micro- and mesoporous materials. Pitfalls and limitations in gas adsorption data analysis. Microporous Mesoporous Mater 60:1-17. https://doi.org/10.1016/S1387-1811(03)00339-1

Guiochon G (2002) Preparative liquid chromatography. J Chromatogr A 965:129-161. https://doi.org/10.1016/S0021-9673(01)01471-6

Gupta B, Begum IZ, Rajput G (2008) Equilibrium and kinetic studies for the adsorption of $\mathrm{Mn}$ (II) and $\mathrm{Co}$ (II) from aqueous medium using agar-agar as sorbent. Chem Eng Commun 195:1200-1212. https://doi.org/10.1080/00986440801905114

Hamdaoui O, Naffrechoux E (2007) Modeling of adsorption isotherms of phenol and chlorophenols onto granular activated carbon: part I. Two-parameter models and equations allowing determination of thermodynamic parameters. J Hazard Mater 147:381-394. https ://doi.org/10.1016/j.jhazmat.2007.01.021

Hassani A, Soltani RDC, Karaca S, Khataee A (2015) Preparation of montmorillonite-alginate nanobiocomposite for adsorption of a textile dye in aqueous phase: isotherm, kinetic and experimental design approaches. J Ind Eng Chem 21:1197-1207. https://doi. org/10.1016/j.jiec.2014.05.034

Hecht H, Srebnik S (2016) Structural characterization of sodium alginate and calcium alginate. Biomacromol 17:2160-2167. https:// doi.org/10.1021/acs.biomac.6b00378

Hetényi M (1996) Maar-type of oil shale in Hungary (in Hungarian). JATE Press, Szeged, pp 1-33

İnal M, Erduran N (2015) Removal of various anionic dyes using sodium alginate/poly(N-vinyl-2-pyrrolidone) blend hydrogel beads. Polym Bull 72:1735-1752. https://doi.org/10.1007/s0028 9-015-1367-7

Joó S, Tóth J, Földényi R (2015) Characterization of salt- and surfactant-containing sandy soil extracts by laser light methods. Int Agrophysics 29:291-298. https://doi.org/10.1515/intag $-2015-0034$

Li J, Jiang Z, Wu H, Long L, Jiang Y, Zhang L (2009) Improving the recycling and storage stability of enzyme by encapsulation in mesoporous $\mathrm{CaCO}_{3}$-alginate composite gel. Compos Sci Technol 69:539-544. https://doi.org/10.1016/j.compscitech.2008.11.017

Liu X, Kaczmarski K, Cavazzini A, Szabelski P, Zhou D, Guiochon G (2002) Modeling of preparative reversed-phase HPLC of insulin. Biotechnol Prog 18:796-806. https://doi.org/10.1021/bp020003a

Nishinari K, Fang Y (2017) Relation between structure and rheologi$\mathrm{cal} /$ thermal properties of agar. A mini-review on the effect of alkali treatment and the role of agaropectin. Food Struct 13:24-34. https://doi.org/10.1016/j.foostr.2016.10.003

Peretz S, Cinteza O (2008) Removal of some nitrophenol contaminants using alginate gel beads. Colloids Surf A Physicochem Eng Asp 319:165-172. https://doi.org/10.1016/j.colsurfa.2007.06.012

Phiri I, Ko JM, Mushonga P, Kugara J, Opiyo Onani M, Msamadya S, Kim SJ, Yeajoon Bon C, Mugobera S, Siyaduba-Choto K, Madzvamuse A (2019) Simultaneous removal of cationic, anionic and organic pollutants in highly acidic water using magnetic nanocomposite alginate beads. J Water Process Eng 31:100884. https ://doi.org/10.1016/j.jwpe.2019.100884

Puguan JMC, Yu X, Kim H (2015) Diffusion characteristics of different molecular weight solutes in Ca-alginate gel beads. Colloids Surf A Physicochem Eng Asp 469:158-165. https://doi.org/10.1016/j. colsurfa.2015.01.027

Rauch R, Földényi R (2020) Investigation of Organic Matter Content of Hungarian Oil Shale and Its Influence on Sorption of 2,4-Dichlorophenol. Period Polytech Chem Eng 64:230-237. https://doi. org/10.3311/PPch.15002

Sang G, Liu S, Zhang R, Elsworth D, He L (2018) Nanopore characterization of mine roof shales by SANS, nitrogen adsorption, and mercury intrusion: impact on water adsorption/retention behavior. Int J Coal Geol 200:173-185. https://doi.org/10.1016/j. coal.2018.11.009

Shawabkeh RA (2006) Adsorption of chromium ions from aqueous solution by using activated carbo-aluminosilicate material from oil shale. J Colloid Interface Sci 299:530-536. https://doi. org/10.1016/j.jcis.2006.02.058 
Solti G (2003) Alginite containing fertilizers, soil mixtures and soil ameliorating agents (in Hungarian). AgrárUnió 4:33-34

Stojanovic R, Belscak-Cvitanovic A, Manojlovic V, Komes D, Nedovic V, Bugarski B (2012) Encapsulation of thyme (Thymus serpyllum L.) aqueous extract in calcium alginate beads. J Sci Food Agric 92:685-696. https://doi.org/10.1002/jsfa.4632

Tanaka H, Matsumura M, Veliky IA (1984) Diffusion characteristics of substrates in Ca-alginate gel beads. Biotechnol Bioeng 26:53-58. https://doi.org/10.1002/bit.260260111

Wang B, Wan Y, Zheng Y, Lee X, Liu T, Yu Z, Huang J, Ok YS, Chen J, Gao B (2019) Alginate-based composites for environmental applications: a critical review. Crit Rev Environ Sci Technol 49:318-356. https://doi.org/10.1080/10643389.2018.1547621

Xu SW, Lu Y, Li J, Zhang YF, Jiang ZY (2007) Preparation of novel silica-coated alginate gel beads for efficient encapsulation of yeast alcohol dehydrogenase. J Biomater Sci Polym Ed 18:71-80. https ://doi.org/10.1163/156856207779146141

Yekeen N, Padmanabhan E, Idris AK, Ibad SM (2019) Surfactant adsorption behaviors onto shale from Malaysian formations: influence of silicon dioxide nanoparticles, surfactant type, temperature, salinity and shale lithology. J Pet Sci Eng 179:841-854. https://doi.org/10.1016/j.petrol.2019.04.096

Yu L, Sun Q, Hui Y, Seth A, Petrovsky N, Zhao CX (2019) Microfluidic formation of core-shell alginate microparticles for protein encapsulation and controlled release. J Colloid Interface Sci 539:497-503. https://doi.org/10.1016/j.jcis.2018.12.075

Zhang Q, Dan S, Du K (2017) Fabrication and characterization of magnetic hydroxyapatite entrapped Agarose composite beads with high adsorption capacity for heavy metal removal. Ind Eng Chem Res 56:8705-8712. https://doi.org/10.1021/acs.iecr.7b01635

Zhang F, Li X, He N, Li T, Sauli E (2015) Novel synthesis of magnetic agar and its application in $\mathrm{Cu}$ ions adsorption. J Nanosci Nanotechnol 15:9721-9724. https://doi.org/10.1166/jnn.2015.10320

Zhao Z, Yuan J, Fu M, Su L, Li Z (2014) Removal of methylene blue from aqueous solution by using oil shale ash. Oil Shale 31:161173. https://doi.org/10.3176/oil.2014.2.06 